\title{
RUANG JEDA INTERAKTIF KEMBANGAN
}

\author{
Gary Santoso ${ }^{1)}$ \\ 1) Program Studi S1 Arsitektur, Fakultas Teknik, Universitas Tarumanagara, gary.santoso08@gmail.com \\ Masuk: 10-01-2020, revisi: 27-01-2020, diterima untuk diterbitkan: 09-05-2020 (doi: 10.24912/stupa.v2i1.6819)
}

\begin{abstract}
Abstrak
Kepadatan perkotaan tidak hanya mempengaruhi perkembangan kota saja tapi dapat berdampak juga pada rutinitas masyarakatnya. Berangkat dari rutinitas inilah kemudian muncul perasaan jenuh dan stres sehingga diperlukan adanya jeda. Jeda yang dimaksud dapat berupa sarana rekreasi untuk keluar dari hiruk pikuk padatnya perkotaan. Masyarakat golongan produktif menjadi golongan yang paling rentan mengalami jenuh dan stres. Ruang jeda diantara padatnya lingkungan perkotaan yang dapat berfungsi sebagai sarana rekreasi yang berada di ruang terbuka, yang juga dapat berfungsi sebagai ruang sosial ditengah padatnya lingkungan perkotaan, berisi kegiatan - kegiatan yang menyehatkan tidak hanya fisik tapi juga secara mental yang diharapkan mampu membantu mengurangi tingkat stress. Kembangan selatan merupakan salah satu wilayah yang memilki tingkat kepadatan yang paling tinggi di Jakarta karena merupakan wilayah sentra primer barat yang artinya wilayah Kembangan Selatan akan menjadi pusat aktivitas terutama di Kawasan Jakarta Barat. Berdasarkan permasalahan tersebut diusulkanlah Ruang Jeda Interaktif Kembangan dengan program utama entertainment yang dibagi menjadi dua fasilitas yaitu rekreasi dan relaksasi sebagai respon terhadap dampak stress yang dihasilkan dari rutinitas masyarakat. Fasilitas rekreasi terbagi menjadi tiga zona yaitu zona perform, playful dan creative play berupa plaza dan area playground sedangkan fasilitas relaksasi berupa zona yang berisi kegiatan untuk melepaskan diri dari kelelahan mental dan fisik seperti yoga, meditasi dan fasilitas kebugaran berupa gym dan lapangan olahraga.
\end{abstract}

Kata kunci: jeda; kepadatan; rekreasi; relaksasi; ruang sosial

\begin{abstract}
Urban density not only affects city development but can also affect the routine of the people. Departing from this routine, a feeling of saturation and stress arises, so a break is needed. The interlude in question can be in the form of recreational facilities to get out of the hustle and bustle of urban dense. Productive groups are the most vulnerable groups experiencing saturation and stress. The space between the dense urban environment that can function as a recreational facility in an open space, which can also function as a social space in a dense urban environment, contains activities that are healthy not only physically but also mentally which are expected to help reduce stress levels. South Kembangan is one of the areas that have the highest density level in Jakarta because it is a western primary center area which means the South Kembangan area will become a center of activity, especially in the West Jakarta Region. Based on these problems, Kembangan Interactive Breathing Space is proposed with the main entertainment program which is divided into two facilities namely recreation and relaxation in response to the impact of stress generated from community routines. Recreational facilities are divided into three zones namely perform, playful and creative play zones in the form of plazas and playground areas while relaxation facilities in the form of zones containing activities to escape mental and physical fatigue such as yoga, meditation, and fitness facilities in the form of gyms and sports fields.
\end{abstract}

Keywords: density; interlude; recreation; relaxation; social space 


\section{PENDAHULUAN}

\section{Latar Belakang}

Kepadatan merupakan salah satu permasalahan utama pada kota - kota besar seperti Jakarta. Perkembangan kota yang semakin pesat tidak hanya membuat lingkungan perkotaan menjadi padat tapi juga berdampak pada rutinitas masyarakatnya. Rutinitas padat yang dilakukan secara terus menerus kemudian menciptakan perasaan jenuh dan stres lalu menciptakan adanya keinginan untuk sekedar berhenti atau keluar sebentar dari rutinitas tersebut sehingga diperlukan adanya jeda. Jeda tersebut dapat berupa sarana hiburan atau rekreasi, keluar dari hiruk pikuk perkotaan, hingga sekedar mengobrol atau bertukar pikiran dengan kerabat. Jeda ini dapat disebut sebagai Third Place ruang antara tempat tinggal dan tempat kerja. Perhatian tertuju pada masyarakat golongan produktif yang paling rentan mengalami stres yang dapat berdampak kehidupan sosial individu masing - masing karena ( Carolyn M. Aldwin, "Stress, Coping and Development").

Walaupun telah banyak hadir tempat rekreasi yang mayoritasnya berada di dalam mall dan masyarakat yang enggan berpergian jauh. Keberadaan tempat rekreasi penghilang stres yang berlokasi di dalam mall dengan kapasitas terbatas pada akhirnya menjadi sangat padat pada akhir pekan sehingga masyarakat yang datang untuk mencari hiburan atau rekreasi malah mendapat hiruk pikuk yang pada akhirnya malah makin stres. Masyarakat Jakarta yang selalu menerima stres dari lingkungan sekitar seperti hiruk pikuk Jakarta sekiranya membutuhkan suasana yang berbeda dalam mengurangi stres. Ruang jeda diantara padatnya lingkungan perkotaan yang dapat berfungsi sebagai sarana rekreasi yang berada di ruang terbuka, yang juga dapat berfungsi sebagai ruang sosial ditengah padatnya lingkungan perkotaan, berisi kegiatan kegiatan yang menyehatkan tidak hanya fisik tapi juga secara mental yang diharapkan mampu membantu mengurangi tingkat stres.

\section{Rumusan Masalah}

Permasalahan yang terjadi pada Kota Jakarta terutama pada kondisi masyarakatnya, antara lain kurangnya fasilitas yang dapat mewadahi kebutuhan masyarakat akan adanya ruang jeda ditengah rutinitas yang padat serta lokasi yang cocok untuk dijadikan ruang jeda.

\section{Batasan Penelitian}

Subjek pada penelitian ini ialah usia produkitf karena merupakan usia yang paling rentan terkena dampak stres. Program yang diusulkan berupa fasilitas rekreasi dan relaksasi yang berlokasi Kelurahan Kembangan Selatan, Kecamatan Kembangan, Jakarta Barat.

\section{Tujuan Penelitian}

Tujuan dari Ruang Jeda Interaktif Kembangan adalah mampu memawadahi kebutuhan jeda pada rutinitas masyarakat yang padat melalui fasilitas rekreasi dan relaksasi yang berupa aktivitas bermain, olahraga hingga meditasi. Fasilitas yang dihasilkan tidak hanya berfungsi sebagai saran hiburan saja tetapi dapat juga berfungsi sebagai ruang sosial atau ruang komunal.

\section{KAJIAN LITERATUR}

\section{Third Place}

Arsitektur berkembang berdasarkan kebutuhan masyarakat. Third Place merupakan kebutuhan masyarakat, selain dari rumah (first place) dan tempat kerja (second place). Third place merupakan tempat publik yang netral, yang dapat dikunjungi oleh siapa saja dan dapat digunakan untuk berbagai aktivitas yang beragam sesuai dengan kehidupan dan budaya masyarakatnya. Third place merupakan sebuah anchor yang berfungsi sebagai tempat bagi komunitas yang ada, tempat yang mempertemukan masyarakat disekitarnya.Open Architecture menjadi kesempatan untuk menciptakan sebuah platform arsitektur yang dapat dikombinasikan dengan berbagai macam keadaan masyarakat yang berdasarkan commercial, hospitality dan entertainment. Ketiga kategori ini dibutuhkan masyarakat perkotaan. Masyarakat kota 
sangatlah majemuk yang berarti sangat beragam sehingga akan menimbulkan berbagai macam konflik karena penyatuan berbagai macam program yang berlawanan.

Third Place cukup unik dalam pengembangan konsepnya karena dapat digunakan oleh beberapa generasi tidak hanya anak-anak tapi orang yang telah lanjut usia juga dapat menggunakannya, seperti adanya jalur sepeda dan akses pejalan kaki yang terhubung dengan sarana transportasi umum ataupun tempat rekreasi/hiburan lainnya. Ketika berkumpul, setiap individu dapat saling bertemu, bertukar pikiran, mengeluarkan pendapat, belajar, bermain dan sebagainya. Kegiatan seperti ini akan menimbulkan ikatan berdasarkan intrest yang disukainya, namun dalam masyarakat modern, yang sangat individual, diperlukan suatu event atau program yang mampu menghubungkan satu dengan lainnya.

Karakteristik Third Place berdasarkan Ray Oldenburg's:

- Neutral Ground

Berada diatas tapak yang tidak terikat secara finasial, politik dan siapa pun bebas untuk datang dan pergi.

- Leveler (a leveling place)

Third place tidak mementingkan status sosial ataupun ekonomi seseorang. Tidak ada persyaratan bagi seseorang untuk berpartisipasi dalam Third Place.

- Conversation is the main activity

Tempat bertukar pikiran atau informasi merupakan fokus aktivitas yang utama.

- Accessibility and accommodation

Mampu terbuka dan dapat dijangkau dari manapun serta dapat mengakomodasi kebutuhan disekitarnya.

- $\quad$ The regulars

Mampu memberikan karakteristik pada kawasan sehingga dapat memberikan suasana yang nyaman bagi pengunjung yang baru datang ke kawasan tersebut.

- A low profile

Tidak membeda - bedakan pengunjung yang datang, semua kalangan diterima baik dari anak - anak, remaja, dewasa hingga orang tua.

- The mood is playful

Percakapan didalam third place tidak selamanya membahas hal-hal yang rumit terkadang membahas hal-hal kecil yang dilakukan tanpa adanya tekanan.

- A home away from home

Dapat memberikan suasana seperti berada di rumah sendiri.

\section{Kepadatan}

Menurut Sundstrom kepadatan dapat diartikan sejumlah manusia dalam setiap unit ruangan (Wrightsman \& Deaux, 1981). Suatu keadaan dapat dikatakan semakin padat bila jumlah manusia pada suatu batas ruang tertentu semakin banyak dibandingkan dengan luas ruangannya (Sarwono, 1992).

\section{Stres}

Definisi stres menurut Selye, menganggap stress sebagai respon terhadap berbagai kondisi lingkungan meliputi penderitaan emosional, detoriorasi kinerja dan perubahan fisiologis (Davison, Neale, \& Kring, 2006). Menurut (Santrock, 2002), stres adalah respon individu terhadap keadaan dan kejadian yang mengancam dan beban dalam menangani masalah yang dihadapi. Stres bersifat subjektif karena tergantung dari persepsi bagaimana seseorang menangani suatu masalah atau tekanan.

Stresor merupakan sumber yang menyebabkan stres berupa kondisi stimulasi yang menghasilkan reaksi stres. Menurut Mangoenprasodjo terdapat tiga sumber stres, antara lain: 
- Lingkungan kehidupan yang menuntut penyesuain diri, seperti keluarga, pekerjaan, faktor sekolah, kebisingan, suhu yang terlalu panas dan kesesakan.

- Fisiologis, seperti perubahan kondisi tubuh, haid, hamil, proses menua, reaksi tubuh terhadap ancaman dan perubahan lingkungan.

- Pikiran yang berkaitan dengan pemaknaan diri dan pengalaman konflik.

Dampak stres dapat dibagi menjadi tiga menurut John W Santrock, yaitu:

- Dampak bagi fisik

Secara fisiologis, seseorang yang mengalami stres dapat mengalami gejala - gejala seperti masalah pencernaan, mudah pening hingga kejang otot.

- Dampak bagi psikologis

Secara psikologis stress dapat berakibat pada kecemasan, serangan panik, keletihan emosi hingaa gangguan jiwa.

- Dampak bagi perilaku.

Secara perilaku dapat mengakibatkan frekuensi makan atau tidur menjadi berkurang, gairah hidup berkurang, menarik diri dari pergaulan sosial hingga dapat berakibat pada bunuh diri.

Penanganan stress dapat dilakukan dengan dua cara (Taylor et al., 2005), yaitu:

- Mencegah stres

Dapat dilakukan dengan olahraga, diet, rekreasi, istirahat dan meditasi.

- Coping stress

Upaya untuk mengatasi masalah emosi negatif, dapat dilakukan dengan cara melakukan konsultasi dengan psikolog dan menjalani teknik relaksasi.

\section{Rekreasi}

Definisi rekreasi menurut Henry Pratt ialah suatu aktivitas yang bersifat fisik, mental maupun emosional dan tidak selalu bersifat non aktif. Aktivitas rekreasi dapat dilakukan di sela - sela waktu senggang, sifatnya lebih fleksibel, tidak dibatasi oleh tempat dan dapat dilakukan oleh perorangan maupun berkelompok. Rekreasi berasal dari dua kata, yaitu re dan kreasi yang berarti kembali menggunakan daya fikir untuk mencapai kesenangan melalui suatu kegiatan.

Beberapa hal yang menjadi batasan dalam rekreasi:

- Bersifat sementara karena hanya dilakukan pada waktu luang.

- Tidak terdapat unsur paksaan di dalamnya.

- Dalam melakukan kegiatan rekreasi tidak terikat oleh aturan, waktu dan tempat.

\section{Relaksasi}

Relaksasi menurut Encyclopedia of Healing Therapies adalah suatu kegiatan untuk memfokuskan pikiran agar tubuh menjadi bugar dalam menghadapi stres, beberapa kegiatan relaksasi, yaitu:

- Meditasi.

Bagi masyarakat India meditasi dilakukan sebagai pencerahan spiritual untuk meningkatkan tingkat relaksasi dan inner harmony, selama meditasi pikiran difokuskan terhadap satu aktivitas dan mengabaikan aktivitas lainnya atau gangguna lainnya.

- Hidroterapi

Dalam hidroterapi, air digunakan untuk pengobatan, dapat berupa cairan, es hingga uap. Hidroterapi berasal dari bangsa Yunani dimana ada kepercayaan bahwa air mengandung zat - zat kehidupan. Metode hidroterapi tradisional biasanya terdiri dari mandi, sauna dan kompres sedangkan metode hidroterapi modern menggunakan whirpool dan water jets. 
- Pilates

Latihan dalam pilates menggabungkan kemampuan pernapasan, konsentrasi, fokus dan lebih menitik beratkan dalam melatih kesadaran menggerakkan otot tubuh.

- Pijat

Prinsip dasarnya adalah semua bentuk sentuhan melalui kulit, yang merupakan organ sensor tubuh terbesar. Pijatan dapat membantu menenangkan, secara langsung memberi efek terhadap sistem tubuh yang mengatur detak jantung, tekanan darah,pernafasan dan pencernaan. Perasaan sehat yang dihasilkan oleh pijatan dapat menurunkan jumlah peredaraan hormon stres.

- Yoga

Konsep dalam yoga yaitu menyeimbangkan tubuh dan pikiran melalui gerakan yoga untuk melatih pernapasan, relaksasi dan meditasi. Yoga bermanfaat untuk meningkatkan sirkulasi dan menempatkan tekanan pada sistem kelenjar tubuh yang dapat meningkatkan kesehatan yang lebih baik.

\section{METODE}

\section{Metode Penelitian}
a. Subjek Penelitian : Usia produktif
b. Objek Penelitian : Jalan Pesanggrahan, Kembangan Selatan
c. Unsur yang diteliti
: Kebutuhan masyarakat sekitar, penanganan stres

d. Pengumpulan data
e. Sumber data

a. Kondisi tapak Jalan Pesanggrahan, Kembangan Selatan

: Observasi lapangan dan studi literatur

: Observasi tapak, literatur dan peraturan pemerintah

Pada penelitian ini dimulai dengan mengumpulkan data, menganalisis data, lalu diinterpretasikan. Data yang dikumpulkan berupa unsur-unsur Third place, fasilitas rekreasi dan relaksasi, keadaan tapak, dianalisis untuk menghasilkan Ruang Jeda Interaktif Kembangan

\section{Metode Perancangan}

Metode perancangan yang digunakan ialah Tipologi Ruang Kegiatan (Gunawan Tjahjono, "Metode Perancangan Suatu Pengantar Untuk Arsitek dan Perancang", 2000)kegiatan manusia semuanya memiliki konsekuensi terhadap pemakaian ruang dan syarat yang dihasilkannya. Mempelajari kegiatan menampilkan suatu penyelesaian terhadap masalah yang ditimbulkannya. Dalam menganalisis ruang gerak, tipe adalah kegiatan yang mendasar, sementara model adalah nama ruang tersebut. Pengembangan tipe dibandingkan dengan model, dapat melihat peluang lain yang tidak terikat dengan pengalaman yang pernah dialaminya, dapat mengembangkan dari yang mendasar ke berbagai wujud batas ruang.

Pada perancangan proyek ini diperhatikan terlebih dahulu kegiatan apa saja yang dilakukan di dalam third place agar dapat mengembangkan wujud batas ruang berdasarkan kegiatan tersebut. Kegiatan di dalam third place dapat berupa ngobrol, duduk - duduk santai, hingga aktivitas rekreasi dengan memperhatikan kegiatan yang mendasar tersebut dapat memberikan peluang untuk menciptakan ruang bertipe tukar pikiran, rekreasi dan relaksasi.

\section{DISKUSI DAN HASIL}

\section{Program}

Usulan program utama yaitu entertainment yang terbagi menjadi dua fasilitas, yaitu rekreasi dan relaksasi dilihat berdasarkan kebutuhan kawasan dan hasil studi terkait dengan tema Third Place. Terdapat juga fasilitas penunjang seperti area $F \& B$ dan ruang terbuka hijau. Fasilitas rekreasi dan relaksasi sebagai bentuk respon terhadap dampak stres yang dihasilkan dari rutinitas yang padat dan fasilitas pendukung berupa F\&B karena berdasarkan hasil kuesioner 
salah satu yang dicari oleh orang sebagai tempat nongkrong adalah café. Pengelompokkan program terbagi menjadi 3 zona, yaitu:

- Program Rekreasi, berupa zona yang berisi kegiatan menyangkut perform, playful dan creative play.

- Program Relaksasi, berupa zona yang berisi kegiatan untuk melepaskan diri dari kelelahan mental dan fisik.

- Program Pendukung, berupa zona café, kios, kantor pengelola, ruang pengajar dan ruang p3k

Fungsi pada program rekreasi, berupa:

- Perform, melibatkan kegiatan yang menyangkut pertunjukkan seni dan musik, berupa plaza berbentuk amphitheather.

- Playful, melibatkan kegiatan yang menyangkut area bermain tidak hanya untuk anak - anak saja tapi dari usia remaja dan dewasa, seperti playground, outdoor gym, game center, wall climbing hingga lapangan basket.

- Creative Play, melibatkan kegiatan yang menyangkut imajinasi dan seni, seperti area mural.

Fungsi pada program relaksasi, berupa:

- Fisik : : Gym, lapangan badminton dan area ping pong

- Mental : Studio yoga dan taman meditasi

Fungsi pada program pendukung, berupa:

- Café

- Kios

- Kantor Pengelola

- Ruang Pengajar

- Ruang P3K

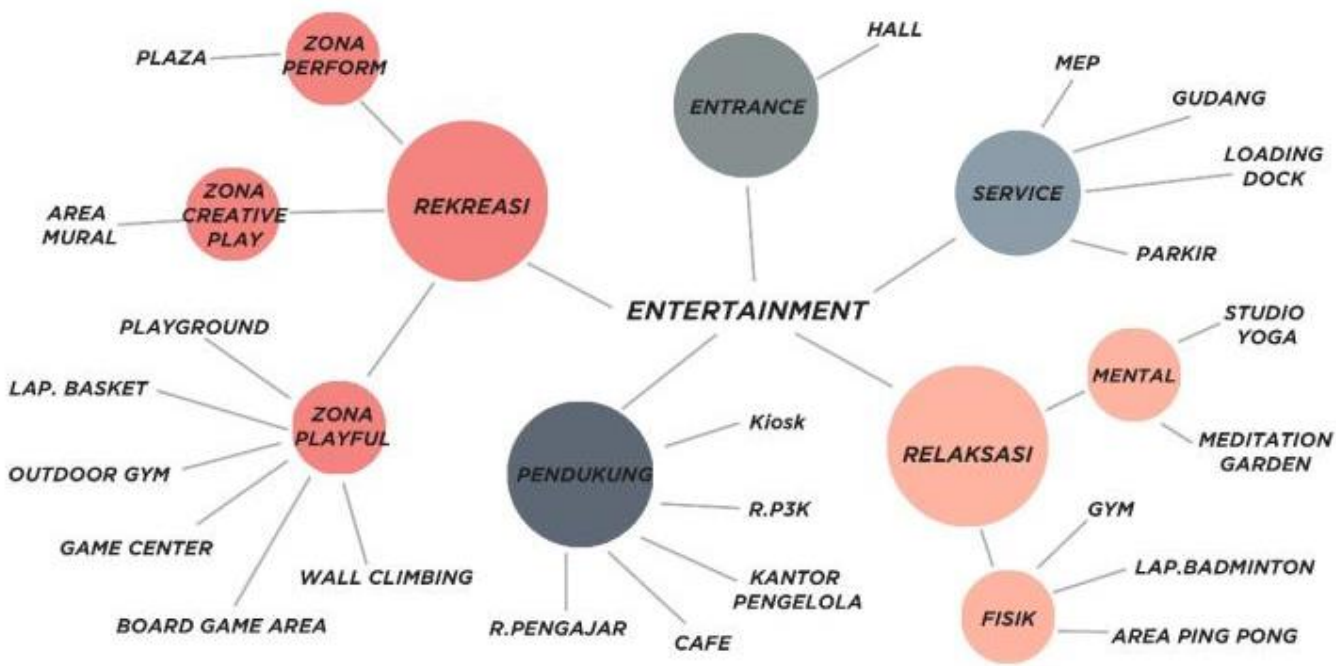

Gambar 1. Diagram Program Bangunan

Sumber: Penulis, 2019

\section{Lokasi Site}

Pemilihan kawasan dipilih berdasarkan karakteristik third place, isu yang ingin diangkat yaitu mengenai masalah kepadatan serta kawasan dengan peruntukkan lahan yang beragam atau heterogen, tidak hanya berisi zona hunian tapi terdapat juga zona perkantoran, perdagangan 
dan jasa karena third place itu sendiri merupakan ruang antara. Secara peruntukkan lahan Kecamatan Kembangan lebih di dominasi oleh zona hunian (warna kuning). Zona Perkantoran, Perdagangan dan Jasa (warna ungu tua) serta zona campuran (warna orange) lebih mendominasi pada Kelurahan Kembangan Selatan. Banyaknya zona yang beragam ini dapat meningkatkan potensi pengguna serta memberikan peluang untuk menciptakan adanya ruang jeda atau third place.

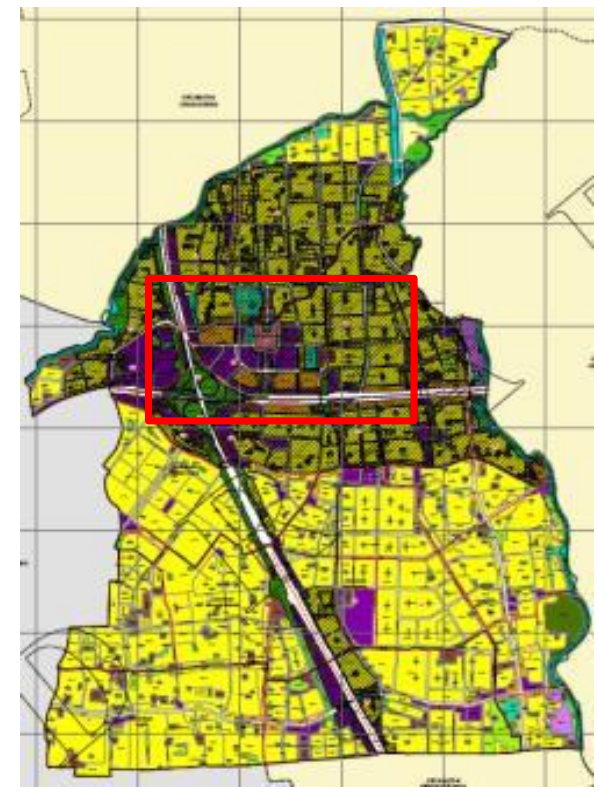

Gambar 2. Zonasi Kawasan Kembangan

Sumber: Penulis, 2019

Sentra Primer Barat berada di Kecamatan Kembangan, tepatnya di Kelurahan Kembangan Selatan, berdasarkan visi dan misi Pengembangan Tata Ruang Kotamadya dengan difokuskannya sebagai pusat kegiatan wilayah maka dalam beberapa tahun ke depan wilayah ini akan menjadi sangat padat sehingga kawasan ini sesuai dengan isu kepadatan yang ingin diangkat. Kembangan Selatan jika dilihat lebih detail lagi merupakan wilayah kelurahan yang paling memiliki zonasi heterogen sehingga Kembangan Selatanlah yang dipilih.

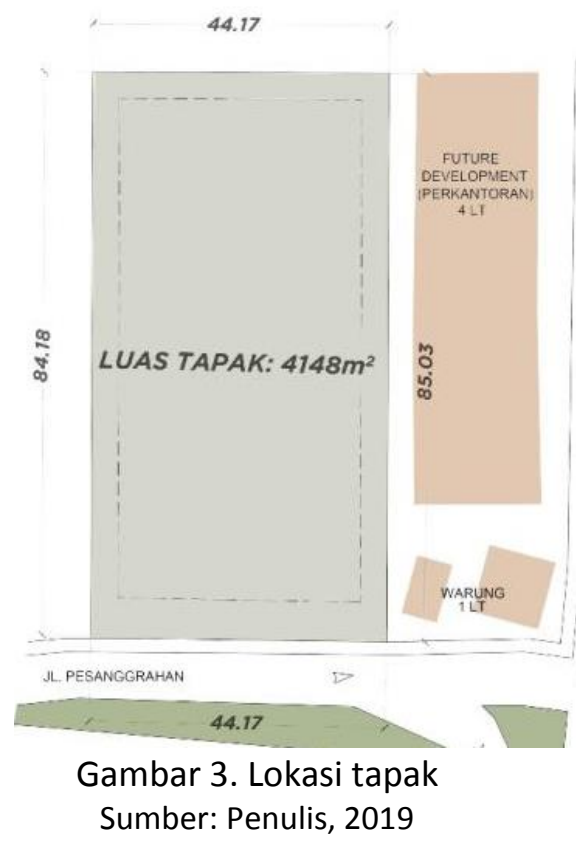


Tapak berada di jalan Pesanggrahan. Tapak berbentuk memanjang kebelakang dengan hanya satu akses masuk dan keluar karena pada sisi samping kiri kanan dan belakang dikelilingi oleh perumahan warga. Peruntukkan lahan pada tapak ialah Perkantoran KDB Rendah sehingga secara peraturan lokasi tapak dapat dibangun tempat rekreasi dan relaksasi. Tapak berada dekat dengan halte transportasi kendaraan umum, yang dilalui oleh beberapa transportasi umum, seperti KWK B09, KWK B10, KWK B14 dan Metro mini M48 dengan jarak kurang dari 50m dari tapak sehingga dapat ditempuh dengan berjalan kaki.

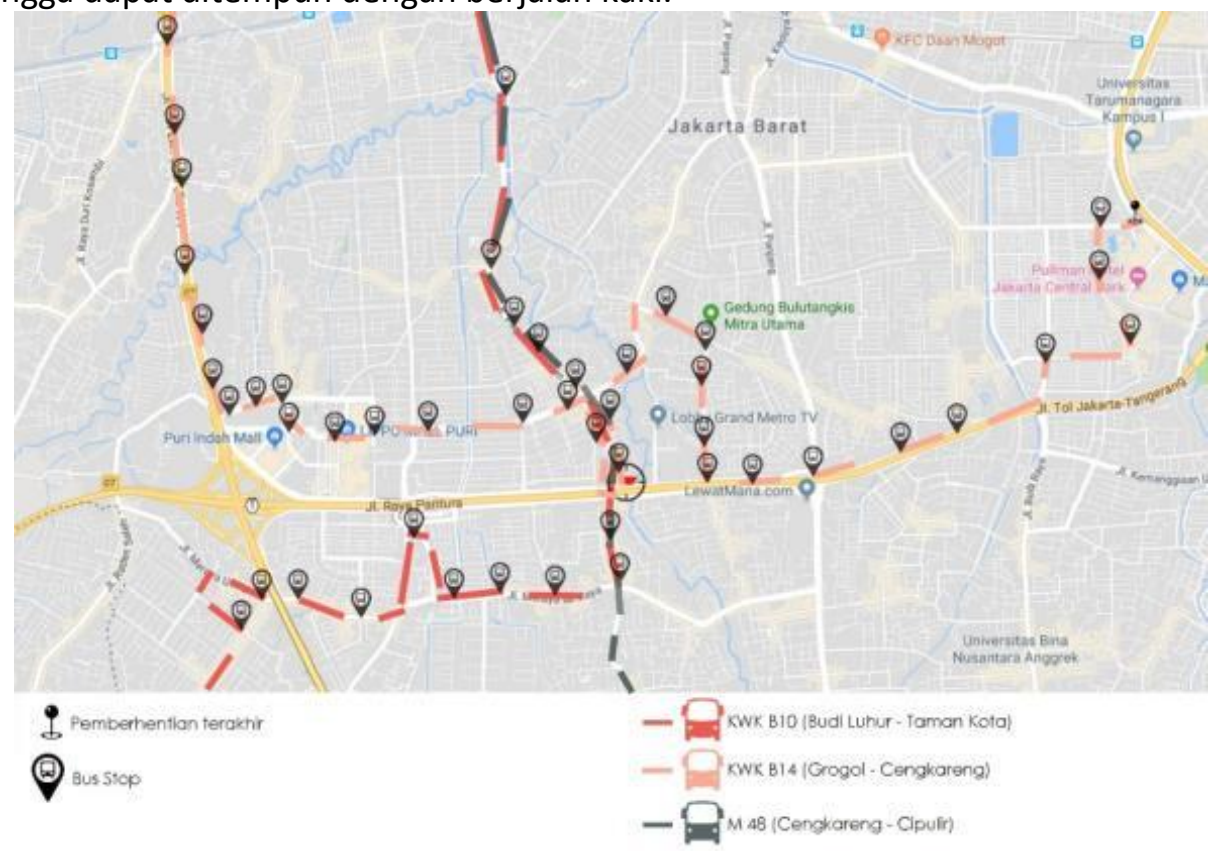

Gambar 4 Titik pemberhentian angkutan umum Sumber: Penulis, 2019

\section{Konsep Bangunan}
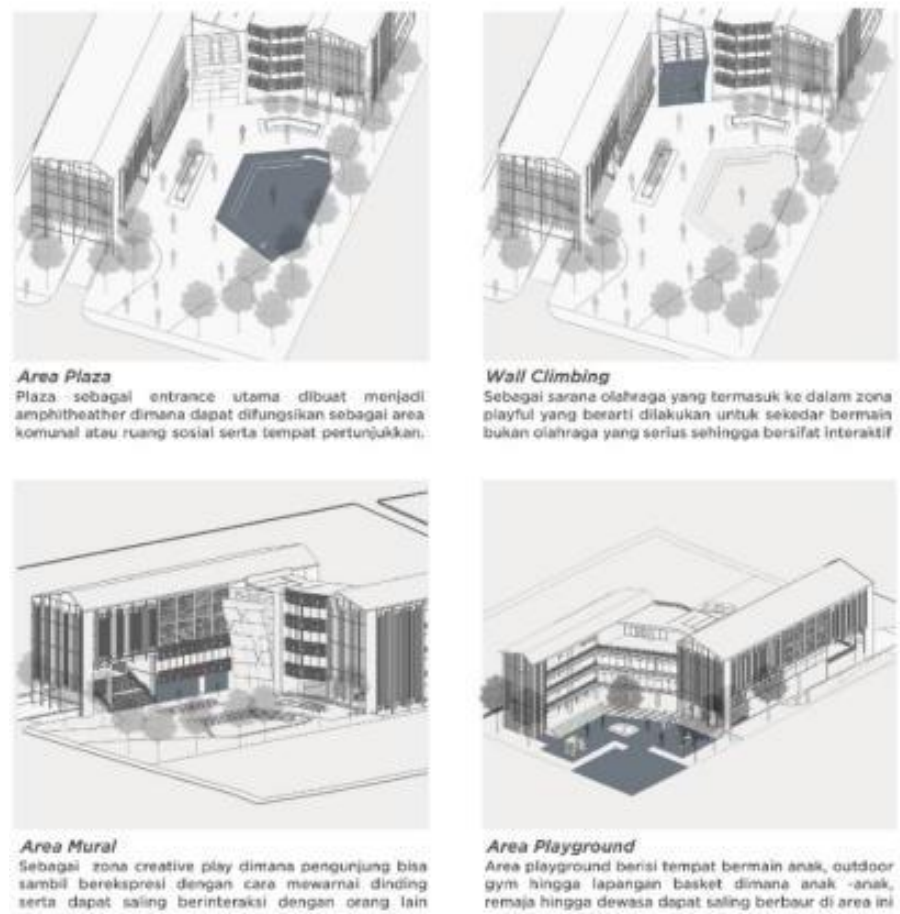

Gambar 5 Diagram konsep

Sumber: Penulis, 2019 
Plaza sebagai entrance utama dibuat menjadi amphitheather dimana dapat difungsikan sebagai area komunal atau ruang sosial serta tempat pertunjukkan. Wall Climbing sebagai sarana olahraga yang termasuk ke dalam zona playful yang berarti dilakukan untuk sekedar bermain bukan olahraga yang serius sehingga bersifat interaktif. Area mural Sebagai zona creative play dimana pengunjung bisa sambil berekspresi dengan cara mewarnai dinding serta dapat saling berinteraksi dengan orang lain. Area playground berisi tempat bermain anak, outdoor gym hingga lapangan basket dimana anak -anak, remaja hingga dewasa dapat saling berbaur di area ini.

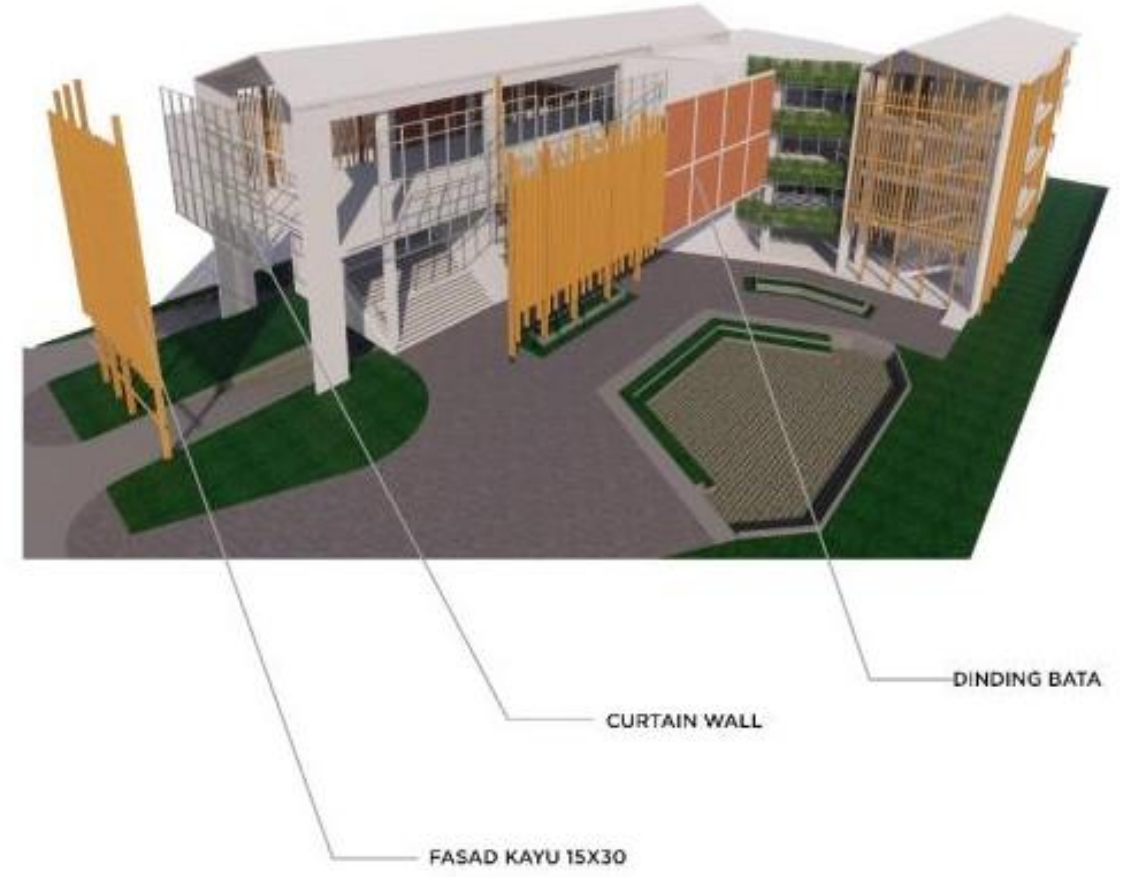

Gambar 6 Diagram fasad

Sumber: Penulis, 2019

Penggunaan fasad kayu untuk mengurangi sinar matahari yang masuk ke dalam banguanan dimana sisi entrance bangunan mengarah ke arah barat laut sedangkan Penggunaan fasad bata disusun memiliki celah kecil sehingga dapat dilalui oleh angin , untuk membantu menerapkan sistem cross ventilation ke dalam bangunan.

\section{Hasil Bangunan}

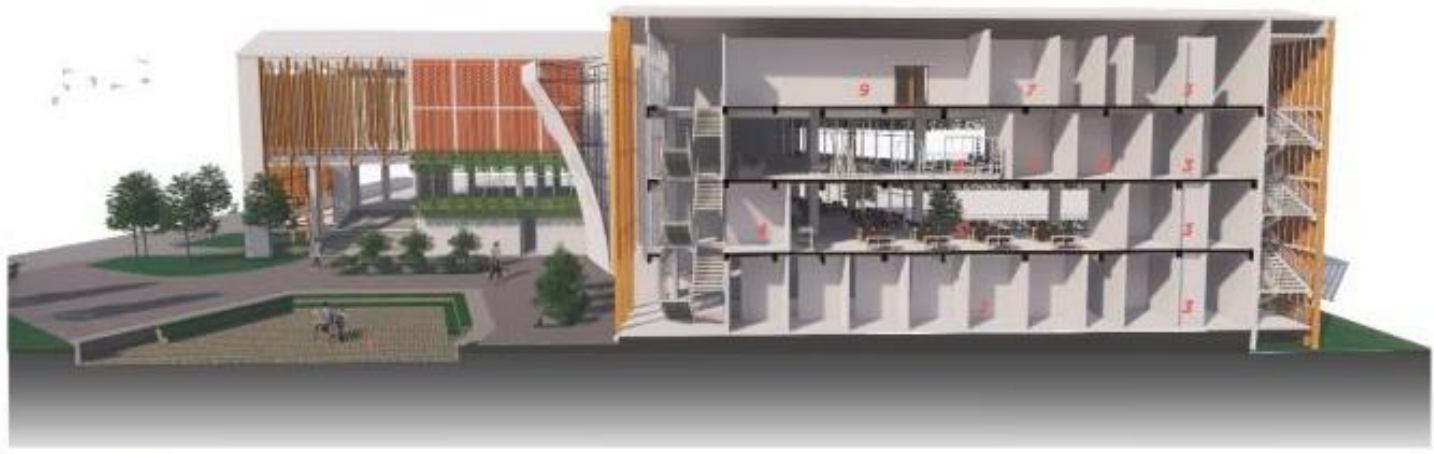

Gambar 7 Potongan persepektif

Sumber: Penulis, 2019 
Lantai 1 lebih difokuskan untuk area publik seperti plaza, area mural, wall climbing, playground, outdoor gym dan lapangan basket. Lantai 2 berisi game center, board game area dan café. Lantai 3 lebih difokuskan untuk aktivitas kebugaran berupa gym dan lapangan badminton sedangkan lantai 4 berisi aktivitas yang lebih difokuskan pada mental seperti area meditasi dan studio yoga. Area service dan parkiran diletakkan pada lantai basement. Pada sistem sirkulasi vertikal penggunaan tangga lebih dominan, hanya terdapat 2 lift, 1 lift barang dan 1 lift yang diperuntukkan untuk difable hal ini dilakukan agar para pengunjung yang datang dapat lebih banyak beraktivitas salah satunya dengan cara naik tangga

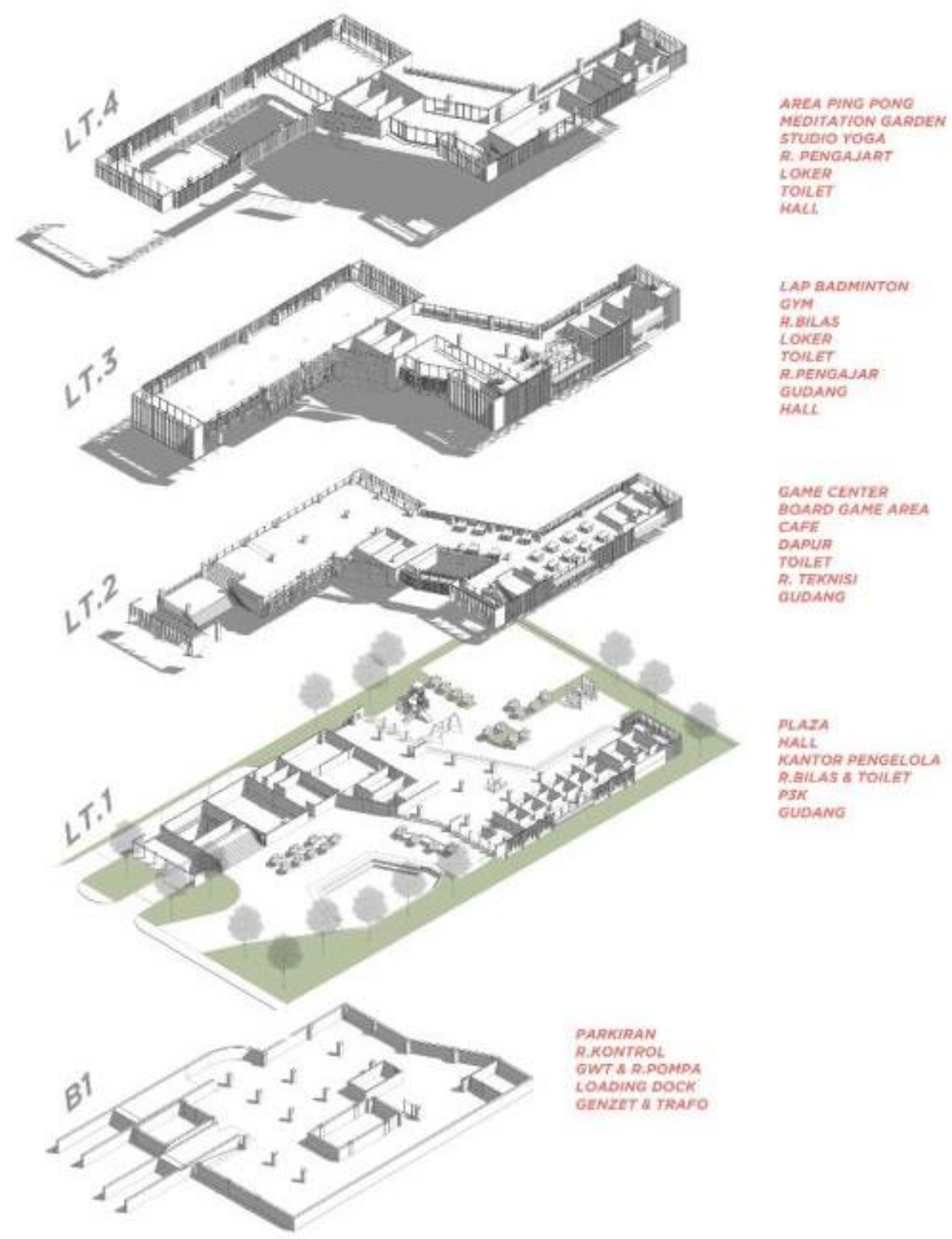

Gambar 8 Axonometri denah

Sumber: Penulis, 201 


\section{KESIMPULAN DAN SARAN}

\section{Kesimpulan:}

a. Fasilitas yang dapat dihasilkan untuk mewadahi kebutuhan masyarakat akan ruang jeda ialah penggabungan fasilitas rekreasi dan relaksasi menjadi fasilitas entertainment karena menurut Taylor, Henry Pratt dan Encyclopedia of Healing Therapies fasilitas tersebut dibutuhkan sebagai pembentuk penanganan terhadap stres akibat rutinitas yang padat, dengan program yang diusulkan berupa kegiatan bermain, olahraga, hingga meditasi dan yoga, dimana fasilitas rekreasi dan relaksasi tersebut juga dapat berfungsi sebagai ruang sosial atau komunal.

b. Lokasi yang dipilih sebagai ruang jeda ialah Kawasan Kembangan Selatan karena merupakan kawasan Sentra Primer Barat yang berarti pusat kegiatan akan difokuskan dikawasan tersebut sehingga Kawasan Kembangan Selatan akan menjadi sangat padat serta memiliki akses tol dan angkutan umum sehingga dari segi pencapaian cukup mudah dijangkau.

Saran:

Perasaan jenuh yang dibiarkan secara terus menerus dapat mengakibatkan stres, salah satu bentuk penangganan stres dapat dilakukan dengan cara berolahraga, rekreasi dan relaksasi sehingga penggabungan fasilitas - fasilitas tersebut menjadi sebuah ruang jeda diharapkan mampu menjadi wadah bagi masyarakat yang ingin berhenti atau istirahat sejenak dari rutinitasnya.

\section{REFERENSI}

Aldwin, C. M. (2007). Stress, coping, and development: An integrative perspective (2nd ed.). Oldenburg, R. (1989). The Great Good Place: Cafes, Coffee Shops, Community Centers, Beauty Parlors, General Stores, Bars, Hangouts, and How They Get You Through the Day.

Jeffres, Leo W.; Bracken, Cheryl C.; Jian, Guowei; Casey, Mary F. "The Impact of Third Places on Community Quality of Life". Applied Research in the Quality of Life. 4 (4): 333-345

Richard J. Diedrich, \& Stephen A. Kliment. (2005). Building type basics for recreational facilities. John Wiley \& Sons.

Santrock, J.W. (2002). Life Span Development (Perkembangan Masa Hidup, Jilid 2, Penerjemah: Chusairi dan Damanik). Jakarta: Erlangga.

Sarwono, S. (1992). Psikologi Lingkungan. Jakarta: Gramedia.

Taylor, J. and Evans, D. (2005) 'Pulling together: keeping track of pedagogy, design and evaluation through the development of scenarios - A case study', in special issue of Journal of Educational Media, publication due 2005.

The Creation of Place Design Team White Papers diperoleh dari http://www.embracetheplace.com/wpcontent/themes/EtP\%20Theme/docs/3thirdplaces.p df

Tjahjono, G (2000). Metode Perancangan Suatu Pengantar Untuk Arsitek dan Perancang. Jakarta: Universitas Indonesia

Woodham, A., \& Peters, D. (1997). Encyclopedia of Healing Therapies

Wrightsman, dan Deaux. (1981). Social Psychology in the 80's. Monterey, California: Brools. 
